\title{
Under-utilization of antenatal care services in Timor-Leste: results from Demographic and Health Survey 2009-2010
}

Vishnu Khanal ${ }^{1 *}$, Jonia Lourenca Nunes Brites da Cruz ${ }^{2}$, Shiva Raj Mishra', Rajendra Karkee ${ }^{3}$ and Andy H. Lee ${ }^{4}$

\begin{abstract}
Background: Timor-Leste is a young country in the Asia-Pacific region with a high maternal mortality rate of 557 per 100,000 live births. As most maternal deaths can be prevented by providing quality antenatal care (ANC) and skilled assistance during childbirth, understanding the barriers to the utilization of ANC services can enhance program implementation. This study aimed to investigate the prevalence and factors associated with the under-utilization of ANC services in Timor-Leste.
\end{abstract}

Methods: Timor-Leste Demographic and Health Survey (TDHS) 2009-2010 was a nationally representative multi-stage cross-sectional study involving 11,463 households and 9,828 childbirths. Information on last born child was recorded for 5,895 mother-child pairs. Factors influencing under-utilization of ANC were assessed using hierarchical logistic regression analysis.

Results: Only 3311 (55.2, 95 \% confidence interval (Cl) 53.1 to $57.3 \%$ ) made the recommended four ANC visits, while 2584 (44.8; $95 \%$ Cl 42.7 to $46.9 \%$ ) of them reported attending three or less ANC services. Significant factors positively associated with the under-utilization of ANC were low wealth status (odds ratio (OR) 2.09; $95 \% \mathrm{Cl} 1.68$ to 2.60), no maternal education (OR 1.54; $95 \% \mathrm{Cl} 1.30$ to 1.82) or primary maternal education (OR $1.21 ; 95 \% \mathrm{Cl} 1.04$ to 1.41), no paternal education (OR 1.34; $95 \% \mathrm{Cl} 1.13$ to 1.60), and having a big problem in permission to visit health facility (OR $1.65 ; 95 \% \mathrm{Cl} 1.39$ to 1.96$)$.

Conclusions: Despite the apparently good progress made in re-establishing the healthcare infrastructure, $45 \%$ of mothers remained in need of a focused intervention to increase their use of ANC services. Further prenatal care program should pay attention to women with low wealth status and those and their partners who are uneducated. Moreover, women should be encouraged to make decision on their own health.

\section{Background}

Worldwide, almost 300,000 maternal deaths were reported in 2013 [1], with majority of these deaths occurred in developing countries. Maternal mortality ratio is 14 times higher in developing countries than in developed countries [2]. A large majority of these maternal deaths are preventable by providing quality antenatal care (ANC) and assisting child birth via skilled birth attendants. Maternal mortality has decreased globally by $1.3 \%$ per year since 1990 [1], largely due to a better access to maternal health care. In addition to preventing maternal deaths, it is estimated that $12 \%$ of neonatal deaths could be averted

\footnotetext{
* Correspondence: khanal.vishnu@gmail.com

${ }^{1}$ Nepal Development Society, Bharatpur, Nepal

Full list of author information is available at the end of the article
}

through ANC at $90 \%$ coverage [3]. Attendance of ANC visits during pregnancy is associated with a higher use of institutional delivery service in India, Nepal and other developing countries [4-6]. It provides a platform for services whereby the health of woman is maintained during pregnancy, and improves pregnancy outcomes by identifying and managing pregnancy related complications [5]. Women receive information on birth spacing, fetal growth and development, as well as tetanus immunization at their ANC visits. Moreover, ANC contributes towards the prevention and treatment of malaria, management of anemia, and screening and treatment of sexually transmitted infections [7]. Therefore, the World Health Organization (WHO) has recommended at least four focused ANC visits during pregnancy [8]. 
Timor-Leste (East Timor) is a young country in the Asia-Pacific region which suffered a long conflict in the 1990s [9], leading to the destruction of most of its infrastructure, in addition to 200,000 deaths [10] and tens of thousands of its citizens being internally displaced [11]. The country declared its independence in 2002. Despite a shortage of trained health workforce in the post conflict era, the government has since re-established health services with the support from the United Nations, expatriate workers, and the Cuban training programs of medical professionals $[12,13]$. Timor-Leste has a population growth rate of $2.4 \%$ with 1.07 million inhabitants in 2010 [14]. Three quarters $(73.5 \%)$ of its population live in rural areas. The country has a high maternal mortality rate of 557 per 100,000 live births [15]. In addition to constructing new health facilities, the Timorese government has started a community based program to increase the utilization of ANC services. This program is known as "Servisu Integrado Sude Communita" (SISCa) [16] or 'integrated health service program in the community', which provides ANC services through outreach clinics, together with support from local community volunteers to encourage mothers to attend such services.

A large number of studies have investigated factors influencing the use of ANC services in developing countries. For instance, maternal education, parity, maternal autonomy (decision making on her own health), maternal occupation, partner's education, distance to the health facility, and wealth status are known to be associated with the use of ANC [17-19]. Findings from the literature have also suggested that barriers to the utilization of ANC are contextual and may vary across cultures. Understanding such barriers is essential to increase the usage of ANC, in order to minimise any adverse pregnancy outcome. In the case of Timor-Leste, evidence is still lacking on the utilization of ANC services. Although there has been a significant increase in at least one ANC visit from $42.5 \%$ in 2001 to $86 \%$ in 2009 [15], information on attending the four recommended visits remains limited. Therefore, this study aimed to investigate the prevalence and factors associated with the under-utilization of ANC services in Timor-Leste. Results are potentially important for national managers to further monitor and improve the current SISCa maternal health program.

\section{Methods}

This study used the dataset from the Timor-Leste Demographic and Health Survey (TDHS) 2009-2010, which was the second survey conducted since independence. The TDHS was a two stage cluster survey covering the entire nation of 1,163 enumeration areas. During the first stage, 455 enumeration areas were selected by probability sampling proportionate to size. A fixed number of 27 households were then randomly selected from each enumeration area [14]. The national survey has ethics approval from ICF Macro International and Ministry of Health, Timor-Leste [14]. Participants gave consent for themselves whereas mothers or care takers provided consent for minors including infants. The data collection process adhered to World Health Organization's ethical and safety recommendations ([14], p. 227). The first author applied to the measureDHS and obtained permission to use the publicly available data for research and teaching learning purpose. Further details can be obtained from the website of measureDHS (https://dhsprogram.com/ data/Using-DataSets-for-Analysis.cfm).

The TDHS 2009-2010 collected data from 11,463 households representative of the entire nation. The overall response rate was $93.5 \%$. In total, 13,137 women and 4076 men aged 15-49 years were interviewed. The survey used three sets of validated questionnaire (household, men, women) to collect information and the data were subsequently merged in separate datasets for further analyses. The Childrenrecode dataset [20] recorded all 9828 childbirths that occurred within the past five years (URL: http://dhsprogram.com/data/Dataset-Types. cfm). The present study included 5,895 mother-child pairs concerning the last born child only. Two missing and 38 'do not know' cases were subsequently removed from the analyses.

Figure 1 presents the underlying conceptual framework. The outcome variable was 'under-utilization of ANC', i.e. coded 1 if $<4$ ANC visits and coded 0 if $\geq 4$ $\mathrm{ANC}$ visits were made. Independent variables were selected according to the literature and their availability from the database [21], and were grouped into: external factors, pre-disposing factors (socio-demographic and health knowledge factors), enabling factors and need factors [6]. The sole external factor considered was residential location (rural versus urban). Socio-demographic factors included: maternal age ( $\leq 19$ years; $20-34$ years; and 35-49 years), wealth status (rich/upper $20 \%$; middle $40 \%$; and lower $40 \%$ ) [22]; maternal and paternal education (no education; primary school; secondary or higher education), maternal occupation (not working; agriculture; paid job: professional, clerical, business, service; manual job); religion (Roman Catholic; others: Muslim, Protestant, Hindu); maternal final say (decision) on her own health (herself; herself and others; others only); and birth order (rank) $(1 ; 2$ to $3 ; \geq 4)$. The health knowledge factor was taken to be the frequency of watching television (not at all; less than once a week; at least once a week) following previous studies. Enabling factors were whether there was a 'big problem' (major problem) in (a) permission to visit health facility; (b) money to pay for health services; (c) distance to health services; (d) transportation to seek service; (e) presence of companion; and (f) availability of care by female health workers [21]. Need factors 


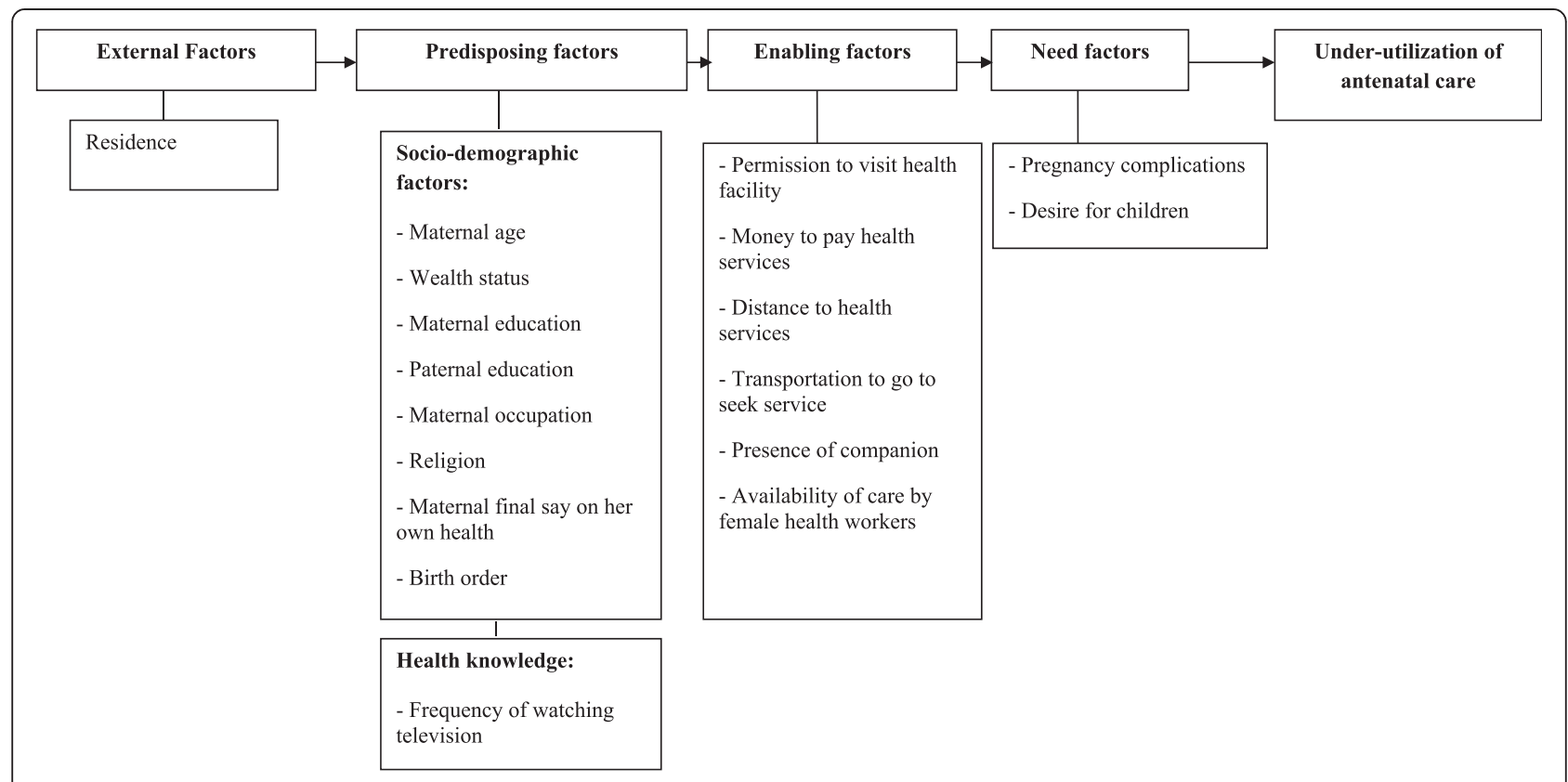

Fig. 1 Conceptual framework of factors associated with under-utilization of antenatal care services in Timor-Leste. Adapted from Titaley et al. [21]

referred to pregnancy complications (severe abdominal pain, severe headache, convulsion, blurred vision and swelling of hands and feet, vaginal bleeding, and other problems that required immediate care) which were classified as either no complication or with complications. Desire for children was recoded into: wanted then; wanted later; and unwanted.

Statistical analyses were performed using the Statistical Package for Social Sciences (SPSS version 20). Data were first summarized by cross tabulation and chi-square tests. Number of ANC visits was presented as frequency distributions and corresponding $95 \%$ confidence intervals (CI). Logistic regression analyses were then undertaken to ascertain the associations between under-utilization of ANC and the aforementioned factors, with adjusted odds ratios (OR) to assess the magnitude of such associations.

A hierarchical modelling strategy was adopted [21-23], with external factors initially entered into the logistic regression model as shown in Fig. 1. Socio-demographic factors were then entered into the model, followed by health knowledge factors, along with significant external and socio-demographic factors. In the final step, enabling factors were added to the model, as the need factors were deemed non-significant according to univariate chi-square tests. Complex sample analyses technique was adopted throughout to account for the study design and sample weight [24].

\section{Results}

Table 1 presents the sample characteristics $(n=5895)$. The majority $(75.4 \%)$ of participants came from rural areas.
Only a small proportion $(2.9 \%)$ of mothers aged $\leq 19$ years. One in five mothers $(20.8 \%)$ had higher socioeconomic status, while about one third $(32.8 \%)$ received no education. Less than a quarter of mothers could decide herself with regard to seeking health care $(23 \%)$ or watched television daily $(24 \%)$. A vast majority $(94.3 \%)$ of them experienced at least one pregnancy complication: severe abdominal pain (37.0 \%), severe headache (42.4\%), convulsion (47.1\%), blurred vision and swelling of hands and feet (11.7 \%), vaginal bleeding (5.7\%), and other problems that required immediate care (26.3\%).

Table 2 gives the frequency distribution of number of ANC visits. Among the 5895 mothers, 2584 were attending three or less ANC services, giving a prevalence of 44.8 \% (95 \% CI 42.7 to $46.9 \%$ ) for under-utilization. Table 1 further shows the univariate associations between the outcome variable and each independent variable, whereas Table 3 presents the set of significant influencing factors in the final logistic regression model. Significant risk factors for under-utilization of ANC were low wealth status (OR 2.09; 95 \% CI 1.68 to 2.60), no maternal education (OR 1.54; $95 \%$ CI 1.30 to 1.82 ) or primary maternal education (OR 1.21; $95 \%$ CI 1.04 to 1.41), no paternal education (OR 1.34; 95 \% CI 1.13 to 1.60), and having a big problem in permission to visit health facility (OR 1.65; $95 \%$ CI 1.39 to 1.96$)$.

\section{Discussion}

This study found that $45 \%$ of the mothers did not attend the recommended four ANC services; among them, $12.6 \%$ reported that they had made no ANC 
Table 1 Characteristics of participants and association with under-utilization of antenatal care, Timor-Leste

\begin{tabular}{|c|c|c|c|c|}
\hline Factors & $n(\%)$ & $\mathrm{ANC} \geq 4$ & ANC $<4^{\mathrm{a}}$ & $P^{*}$ \\
\hline \multicolumn{5}{|l|}{ External Environment } \\
\hline Residence & & & & $<0.001$ \\
\hline Urban & $1351(24.6)$ & $821(28.2)$ & $530(20.2)$ & \\
\hline Rural & $4544(75.4)$ & $2490(71.8)$ & $2054(79.8)$ & \\
\hline \multicolumn{5}{|l|}{ Predisposing Factors } \\
\hline \multicolumn{5}{|l|}{ Socio-demographic } \\
\hline Maternal age (years) & & & & $<0.001$ \\
\hline $15-19$ & $185(2.9)$ & $103(2.8)$ & $82(3.0)$ & \\
\hline $20-34$ & $3518(60.5)$ & 2066 (63.4) & $1452(56.9)$ & \\
\hline $35-49$ & $2192(36.6)$ & $1142(33.8)$ & $1050(40.1)$ & \\
\hline Wealth status & & & & $<0.001$ \\
\hline Low (lower 40 \%) & $2512(39.9)$ & $1141(31.2)$ & $1371(50.7)$ & \\
\hline Middle (middle $40 \%$ ) & $2407(39.3)$ & $1499(43.0)$ & $908(34.7)$ & \\
\hline High (upper 20 \%) & $976(20.8)$ & $671(25.8)$ & 305 (14.6) & \\
\hline Maternal education & & & & $<0.001$ \\
\hline No education & $1980(32.8)$ & 904 (26.6) & $1076(40.5)$ & \\
\hline Primary & $189(27.5)$ & $942(26.9)$ & $747(28.3)$ & \\
\hline Secondary or higher & 2226 (39.6) & $1465(46.6)$ & $761(31.1)$ & \\
\hline Paternal education & & & & $<0.001$ \\
\hline No education & $1658(27.9)$ & $748(22.2)$ & $910(35.1)$ & \\
\hline Primary & $1668(27.4)$ & $945(27.5)$ & $723(27.3)$ & \\
\hline Secondary or higher & $2558(44.6)$ & $1613(50.3)$ & 945 (37.6) & \\
\hline Maternal occupation & & & & $<0.001$ \\
\hline No paid work & $3536(61.0)$ & 1965 (59.7) & $1571(62.7)$ & \\
\hline Agriculture & $1551(24.5)$ & $813(23.1)$ & $738(26.2)$ & \\
\hline Paid work (professional, clerical, sales, service, business) & $675(11.9)$ & $445(14.1)$ & $230(9.2)$ & \\
\hline Paid work (manual) & $125(2.6)$ & $85(3.1)$ & $40(1.9)$ & \\
\hline Religion & & & & 0.597 \\
\hline Roman Catholic & $5770(98.0)$ & $3247(98.1)$ & $2523(97.8)$ & \\
\hline Others & $125(2.0)$ & $64(1.9)$ & $61(2.2)$ & \\
\hline Maternal final say on her own health care & & & & 0.388 \\
\hline Herself & $1391(23.0)$ & $770(22.9)$ & $621(23.2)$ & \\
\hline Herself and others & $3610(64.2)$ & $2076(65.0)$ & $1534(63.2)$ & \\
\hline Others & $683(12.8)$ & $372(12.1)$ & $311(13.6)$ & \\
\hline Birth order & & & & $<0.001$ \\
\hline 1 & $853(14.3)$ & $517(15.5)$ & $336(12.9)$ & \\
\hline $2-3$ & $1655(29.1)$ & 969 (30.6) & $686(27.2)$ & \\
\hline$\geq 4$ & $3387(56.6)$ & $1825(53.9)$ & $1562(60.0)$ & \\
\hline \multicolumn{5}{|l|}{ Health knowledge } \\
\hline Frequency of watching television & & & & $<0.001$ \\
\hline Not at all & $3743(59.9)$ & $1913(53.0)$ & $1830(68.4)$ & \\
\hline Less than once a week & $516(8.4)$ & $323(9.2)$ & $193(7.5)$ & \\
\hline At least once a week & $1636(31.7)$ & $1075(37.9)$ & $561(24.1)$ & \\
\hline
\end{tabular}


Table 1 Characteristics of participants and association with under-utilization of antenatal care, Timor-Leste (Continued)

\begin{tabular}{|c|c|c|c|c|}
\hline \multicolumn{5}{|l|}{ Enabling Factors } \\
\hline Permission to visit health facility & & & & $<0.001$ \\
\hline Big problem & $1379(22.3)$ & $646(18.2)$ & $733(27.4)$ & \\
\hline Not a big problem & $4515(77.7)$ & $2665(81.8)$ & $1850(72.6)$ & \\
\hline Money to pay for health services & & & & $<0.001$ \\
\hline Big problem & $2266(35.1)$ & $1108(30.1)$ & $1158(41.2)$ & \\
\hline Not a big problem & $3629(64.9)$ & $2203(69.9)$ & $1426(58.8)$ & \\
\hline Distance to health facility & & & & $<0.001$ \\
\hline Big problem & $3493(56.0)$ & $1811(51.1)$ & $1682(62.1)$ & \\
\hline Not a big problem & $2400(44.0)$ & $1498(48.9)$ & $902(37.9)$ & \\
\hline Transportation to go to seek service & & & & $<0.001$ \\
\hline Big problem & $3625(61.6)$ & $1892(57.2)$ & $1734(67.1)$ & \\
\hline Not a big problem & $2269(38.4)$ & $1419(42.8)$ & $850(32.9)$ & \\
\hline Presence of companion & & & & 0.002 \\
\hline Big problem & $2594(42.5)$ & $1361(40.3)$ & $1233(45.3)$ & \\
\hline Not a big problem & $3301(57.5)$ & $1950(59.7)$ & $1351(54.7)$ & \\
\hline Availability of care by female health workers & & & & 0.004 \\
\hline Big problem & $3844(64.1)$ & $2101(61.9)$ & $1743(66.7)$ & \\
\hline Not a big problem & $2051(35.9)$ & $1210(38.1)$ & $841(33.3)$ & \\
\hline \multicolumn{5}{|l|}{ Need Factors } \\
\hline Pregnancy complications & & & & 0.451 \\
\hline No complication & $332(5.7)$ & $181(6.0)$ & $151(5.4)$ & \\
\hline With complications & $5563(94.3)$ & $3130(94.0)$ & $2433(94.6)$ & \\
\hline Desire for children & & & & 0.993 \\
\hline Wanted then & $5000(84.4)$ & $2816(84.4)$ & $2184(84.3)$ & \\
\hline Wanted later & $676(12.3)$ & $376(12.3)$ & $300(12.3)$ & \\
\hline Unwanted & $219(3.3)$ & $119(3.3)$ & $100(3.4)$ & \\
\hline
\end{tabular}

${ }^{*}$ Chi-square test of association

ander-utilization of ANC

visits. Being a newly independent country, Timor-Leste has an inadequate infrastructure and limited human resources which may partly attribute to the apparently low utilization of ANC services [25]. The country has been implementing its community-based programs such as integrated community health service (SISCa) and family health promoters ('Promotor Saude Familia') [26]. The promotion of usage of maternal health services remains

Table 2 Frequency distribution of antenatal care visits, Timor-Leste $(n=5,895)$

\begin{tabular}{lll}
\hline ANC visits & Number & Percent $(95 \%$ Cl) \\
\hline 0 & 738 & $12.6(11.3,14.0)$ \\
1 & 200 & $3.2(2.7,3.8)$ \\
2 & 680 & $11.8(10.7,13.0)$ \\
3 & 966 & $17.2(15.9,18.6)$ \\
$\geq 4$ & 3311 & $55.2(53.1,57.3)$ \\
\hline
\end{tabular}

a high priority for the Timor-Leste government and future TDHS may be able to evaluate the effect of such efforts. Decision making power of mothers is found to be a significant factor influencing health service utilization. Not having such power and autonomy of decision has been reported as a major barrier in the utilization of maternity services in Indonesia [21] and Ethiopia [27]. The overall patriarchal society in TimorLeste and low level of maternal education might have contributed to their lack of household decision making, resulting in a high rate of non- utilization of ANC services. Several maternal health promotion programs in developing countries have focused on motivating mothers to attend maternal health services $[16,19]$. However, mothers generally do not have the power to make decision. The current finding therefore indicates the need to educate family members to create an appropriate environment so that mothers can make decision on service 
Table 3 Factors associated with under-utilization of antenatal care in Timor-Leste

\begin{tabular}{|c|c|c|c|}
\hline Factors & $\begin{array}{l}\text { Crude odds ratio } \\
(95 \% \mathrm{Cl})\end{array}$ & $\begin{array}{l}\text { Adjusted odds ratio } \\
(95 \% \mathrm{Cl})\end{array}$ & $P$ \\
\hline Wealth status & & & $<0.001$ \\
\hline High (upper 20 \%) & 1.00 & 1.00 & \\
\hline Low (lower 40 \%) & $2.89(2.36,3.52)$ & $2.09(1.68,2.60)$ & \\
\hline Middle (middle $40 \%$ ) & $1.43(1.19,1.73)$ & $1.18(0.96,1.44)$ & \\
\hline Maternal education & & & $<0.001$ \\
\hline Secondary or higher & 1.00 & 1.00 & \\
\hline No education & $2.28(1.96,2.66)$ & $1.54(1.30,1.82)$ & \\
\hline Primary & $1.58(1.36,1.83)$ & $1.2(1.04,1.41)$ & \\
\hline Paternal education & & & 0.001 \\
\hline Secondary or higher & 1.00 & 1.00 & \\
\hline No education & $2.11(1.80,2.48)$ & $1.34(1.13,1.60)$ & \\
\hline Primary & $1.32(1.14,1.54)$ & $1.00(0.86,1.17)$ & \\
\hline $\begin{array}{l}\text { Permission to visit } \\
\text { health facility }\end{array}$ & & & $<0.001$ \\
\hline Not a big problem & 1.00 & 1.00 & \\
\hline Big problem & $1.70(1.42,2.03)$ & $1.65(1.39,1.96)$ & \\
\hline
\end{tabular}

utilization by themselves [19]. The Timorese Ministry of Health has commenced the "Promotion of Equality Strategy" [15] to support gender sensitive policies. Our finding also provides evidence to support such an initiative.

We found that mothers from households with lower wealth status being at a higher risk of not making the recommended four ANC visits, consistent with national surveys conducted in Indonesia where mothers from poor households tended to be less likely to attend ANC services [21]. Economic hardship may restrict mothers to travel, access and pay for the expenses associated with the use of such services [19]. In addition, they will lose their working hours to earn income which might have a large impact on their livelihood. Recently, financial hardship has been identified as the main reason behind non-compliance to attend ANC [26]. Provision of transportation cost, similar to those implemented in the 'safer mother programme' of Nepal [28], may help to overcome the problem in Timor-Leste.

Influence of parental education on ANC service utilization is well documented [19]. This study similarly found that those mothers with little education and whose partners had no education were less likely to attend the recommended four ANC visits. In general, educated parents have better knowledge on the importance of ANC and ability to decide when and where to seek health care, together with financial resources [29].

Findings of this study are useful for setting a baseline for SISCa [16] and to identify those women who underutilized the ANC services, so that family health promoters can be mobilized [26] at the national level and the next THDS would provide an overall progress in antenatal service. The results suggest targeting those who are poor, less educated, and who are not able to make self-decision for seeking services. If mothers cannot visit the service centres, they should be made aware that current SISCa [16] can bring services to their community. Moreover, health education including knowledge of danger signs of pregnancy and delivery should be advocated, as birth preparedness programs have been found effective in promoting the use of ANC services and subsequent institutional delivery [28].

The present study provides the first report using nationally representative data. The findings have important implications for planning of future studies in maternal health. A major limitation concerns the cross-sectional study designs which was based on recall and self-report. Nonetheless, such methods have been shown to be successful and effective for developing countries whose national source of data is derived from surveys of this nature and magnitude.

\section{Conclusion}

About $45 \%$ of Timorese mothers did not make the recommended four ANC visits. Women with low wealth status, as well as those and their partners who are uneducated, should be targeted to increase their participation in ANC promotion programs. Moreover, women should be encouraged to make decision on their own health via existing community based programs such as SISCa and family health promoters. In the long run, empowering the overall status of women through education would increase their utilization of ANC services.

\section{Competing interests}

The authors declare that they have no competing interests.

\section{Authors' contributions}

VK formulated the study concept, performed statistical analysis and drafted the manuscript. SRM contributed in drafting manuscript, literature review and revision. AHL supervised the project, contributed to data analysis and revision. JDC and RK contributed to literature review and interpretation of findings.

All authors have read and approved the final version for publication.

\section{Acknowledgements}

The authors are grateful to the Measure DHS program of ICF International for permission to use the dataset for this study.

\section{Author details}

${ }^{1}$ Nepal Development Society, Bharatpur, Nepal. ${ }^{2}$ National Hospital Guido Valadares, Ministry of Health, Dili, Timor-Leste. ${ }^{3}$ School of Public Health and Community Medicine, BP Koirala Institute of Health Sciences, Dharan, Nepal. ${ }^{4}$ School of Public Health, Curtin University, Perth, Australia.

Received: 21 December 2014 Accepted: 2 September 2015 Published online: 08 September 2015

\section{References}

1. Kassebaum NJ, Bertozzi-Villa A, Coggeshall MS, Shackelford KA, Steiner C, Heuton KR, et al. Global, regional, and national levels and causes of maternal mortality during 1990-2013: a systematic analysis for the Global Burden of Disease Study 2013. Lancet. 2014;384(9947):980-1004.

2. World Health Organization, UNICEF, UNFPA, The World Bank, United Nations Population Division. Trend in maternal mortality: 1990 to 2010. Geneva: World Health Organization; 2013. 
3. Darmstadt GL, Bhutta ZA, Cousens S, Adam T, Walker N, de Bernis L. Evidence-based, cost-effective interventions: how many newborn babies can we save? Lancet. 2005;365(9463):977-88

4. Ram F, Singh A. Is antenatal care effective in improving maternal health in rural uttar pradesh? Evidence from a district level household survey. J Biosoc Sci. 2006;38(4):433-48.

5. Bloom SS, Lippeveld T, Wypij D. Does antenatal care make a difference to safe delivery? A study in urban Uttar Pradesh, India. Health Policy Plan. 1999;14(1):38-48.

6. Karkee $\mathrm{R}$, Lee AH, Khanal V. Need factors for utilisation of institutional delivery services in Nepal: an analysis from Nepal Demographic and Health Survey, 2011. BMJ Open. 2014;4(3):e004372.

7. AbouZahr C, Wardlaw T. Antenatal care in developing countries: Promises, achievements and missed opportunities-an analysis of trends, levels and differentials, 1990-2001. World Health Organization; 2003.

8. Antenatal care. [http://www.who.int/gho/maternal_health/reproductive_ health/antenatal_care_text/en/] Accessed date: 8 November, 2014

9. Silove D, Brooks R, Bateman Steel CR, Steel Z, Hewage K, Rodger J, et al. Explosive anger as a response to human rights violations in post-conflict Timor-Leste. Soc Sci Med. 2009;69(5):670-7.

10. Indonesia: Power and Impunity: Human Rights under the New Order [http://www.unhcr.org/refworld/docid/3ae6a9b9c.html] Accessed date: 8 November, 2014

11. Wassel T. Timor-Leste: Links between Peacebuilding, Conflict Prevention and Durable Solutions to Displacement. In. Washingtong DC, USA: The Asia Foundation, Timor-Leste; 2014.

12. Cabral J, Dussault G, Buchan J, Ferrinho P. Scaling-up the medical workforce in Timor-Leste: challenges of a great leap forward. Soc Sci Med. 2013;96:285-9.

13. Wayte K, Zwi AB, Belton S, Martins J, Martins N, Whelan A, et al. Conflict and development: challenges in responding to sexual and reproductive health needs in Timor-Leste. Reprod Health Matters. 2008;16(31):83-92.

14. National Statistics Directorate (NSD), Ministry of Finance. Timor-Leste Demographic and Health Survey 2009-2010 Dili, Timor-Leste: ICF Macro, Calverton, USA; 2010

15. Richards E. The Catholic Church and reproductive health and rights in Timor-Leste: contestation, negotiation and cooperation. Cult Health Sex 2014;1-16. Epub ahead of print.

16. Ministry of Health: Strengthen Communities in the area of Health Through SISCa Servisu Integradu da Saúde Communitária (Integrated Community Health Services) In. Dili, Timor Leste: Ministry of Health, Democratic Republic of Timor Leste; 2010

17. Asweto CO, Aluoch JR, Obonyo CO, Ouma JO. Maternal autonomy, distance to health care facility and ANC attendance: findings from madiany division of siaya county, Kenya. Am J Public Health Res. 2014;2(4):153-8.

18. Bernardes AC, da Silva R, Coimbra L, Alves MTSSB, Queiroz RCS, Batista RF, et al. Inadequate prenatal care utilization and associated factors in Sao Luis, Brazil. BMC Pregnancy Childbirth. 2014;14(1):266.

19. Simkhada $B$, Teijlingen ERV, Porter $M$, Simkhada P. Factors affecting the utilization of antenatal care in developing countries: systematic review of the literature. JAN. 2008;61(3):244-60.

20. Measure DHS: Demographic and Health Surveys. [http://www.measuredhs. com/what-we-do/survey/survey-display-356.cfm] Accessed date: 06 February, 2014

21. Titaley C, Dibley M, Roberts C. Factors associated with underutilization of antenatal care services in Indonesia: results of Indonesia Demographic and Health Survey 2002/2003 and 2007. BMC Public Health. 2010;10(1):485.

22. Khanal V, Lee A, da Cruz JLN, Karkee R. Factors associated with nonutilisation of health service for childbirth in Timor-Leste: evidence from the 2009-2010 Demographic and Health Survey. BMC Int Health Hum Rights. 2014;14(1):14.

23. Victora CG, Huttly SR, Fuchs SC, Olinto MT. The role of conceptual frameworks in epidemiological analysis: a hierarchical approach. Int J Epidemiol. 1997;26(1):224-7.

24. West BT. Statistical and methodological issues in the analysis of complex sample survey data: practical guidance for trauma researchers. J Trauma Stress. 2008;21(5):440-7.

25. Wild KJ. Maternity waiting homes and the shaping of maternal health policy in Timor-Leste. 2011.

26. Sarmento DR. Traditional birth attendance (TBA) in a health system: what are the roles, benefits and challenges: a case study of incorporated TBA in Timor-Leste. Asia Pac Fam Med. 2014;13(1):1-9.
27. Woldemicael G, Tenkorang E. Women's autonomy and maternal health-seeking behavior in Ethiopia. Matern Child Health J. 2010;14(6):988-98.

28. Karkee R, Lee AH, Binns CW. Birth preparedness and skilled attendance at birth in Nepal: implications for achieving millennium development goal 5. Midwifery. 2013;29(10):1206-10.

29. Gupta S, Yamada G, Mpembeni R, Frumence G, Callaghan-Koru JA Stevenson $\mathrm{R}$, et al. Factors associated with four or more antenatal care visits and its decline among pregnant women in Tanzania between 1999 and 2010. PLoS One. 2014;9(7), e101893.

\section{Submit your next manuscript to BioMed Central and take full advantage of:}

- Convenient online submission

- Thorough peer review

- No space constraints or color figure charges

- Immediate publication on acceptance

- Inclusion in PubMed, CAS, Scopus and Google Scholar

- Research which is freely available for redistribution

Submit your manuscript at www.biomedcentral.com/submit 